\title{
RESULTS OF IRRADIATED CLADDING TESTS AND CLAD PLATE EXPERIMENTS ${ }^{\star}$
}

F. M. Haggag and S. K. Iskander

Oak Ridge National Laboratory

P.O. Box 2008

Oak Ridge, Tennessee 37831

CONF-8810155--24

DE89 004187

\section{ABSTRACT}

Two aspects critical to the fracture behavior of three-wire stainless steel cladding were investigated by the Heavy-Section Steel Technology (HSST) Program: (1) radiation effects on cladding strength and toughness, and (2) the response of mechanically loaded, flawed structures in the presence of cladding (clad plate experiments).

Postirradiation testing results show that, in the test temperature range from -125 to $288^{\circ} \mathrm{C}$, the yield strength increased, and ductility insignificantly increased, while there was almost no change in ultimate tensile strength. All cladding exhibited ductile-tobrittle transition behavior during Charpy impact testing. Radiation damage decreased the Charpy upper-shelf energy by 15 to 208 and resulted in up to $28^{\circ} \mathrm{C}$ shifts of the Charpy impact transition temperature. Results of irradiated 12.5 -mm-thick compact specimens (0.5TCS) show consistent decreases in the ductile fracture toughness, ${ }^{I} I_{c}$, and the tearing modulus. Results from clad plate tests have shown that (1) a tough surface layer composed of cladding and/or heat-affected zone has arrested running flaws under conditions where unclad plates have ruptured, and (2) the residual load-bearing capacity of clad plates with large subclad flaws significantly exceeded that of an unclad plate.

\section{INTRODUCTION}

The ability of stainless steel cladding to enhance the fracture resistance of an operating nuclear reactor pressure vessel, particularly during certain overcooling transients, depends greatly on the properties of the irradiated cladding. Therefore, weld overlay cladding irradiated at temperatures and to fluences relevant to power reactor operation was examined. Two weld cladding procedures were chosen for the two phases of this study, namely, the singlewire oscillating submerged-arc and the three-wire series arc. The primary differences between these procedures are in the heat input and the resulting

*Research sponsored by the Office of Nuclear Regulatory Research, Division of Engineering, U.S. Nuclear Regulatory Commission under Interagency Agreement DOE 1886-8011-9B with the U.S. Department of Energy under contract DE-AC05-840R21400 with Martin Marietta Energy Systems, Inc.

\section{MASTER}

AISTREOUTHON OF THIS, QPGUMENT IS UNLIAITEO
"The submitied memuacript has basen euthored by a controctor of the U.S. Governmint under contract No. DEACOS-610A2 1400. Accordingty. the U.S. Goverrient retains o nonercluarve. royetry-tron license to publish or reproduce the outinatied form of this confribution. of slow othen to do so. For U.S. Bovernment purposes." 
amounts of base metal dilution of the stainless steel cladding. In the first phase, reported previously in Refs. 1-3, Charpy V-notch (CVN) impact and tensile specimens from a three-layer stainless steel weld overlay fabricated using the single-wire procedure were irradiated to $2 \times 10^{19}$ neutrons $/ \mathrm{cm}^{2}$ $(>1 \mathrm{MeV})$ at $288^{\circ} \mathrm{C}$. Cladding from the upper weldment layers, typical of good quality pressure vessel cladding, exhibited very little irradiation-induced degradation. However, ductile-to-brittiè transition behavior, caused by temperature-dependent failure of the residual delta-ferrite, was observed during impact testing. In contrast, specimens from the first weldment layer, which also exhibited transition type behavior, were markedly embrittled. The cause of the embrittlement was determined to be high radiation sensitivity of the atypical microstructure resulting from excessive base metal dilution of the first weldment layer.

In the second phase, the first subject of this paper, a commercially produced three-wire series-arc stainless steel cladding was evaluated under similar irradiation (except for the high fluence specimens) and testing conditions as in the first phase. The results of tensile and CVN tests were reported earlier; however, a summary is provided here together with the results of irradiated and unirradiated $12.5-\mathrm{mm}$-thick compact specimens (0.5TCS).

The objective of the clad plate program, the second subject of this paper, is to determine the effect of three-wire stainless steel cladding upon the propagation of small surface cracks subjected to stress states similar to those occurring during a pressurized thermal shock (PTS) scenario. The potential benefit to the U.S. Nuclear Regulatory Commission is an improved predictive capability of the fracture strength of a reactor pressure vessel (RPV) with hypothetical. flaws. The objectives of this research were achieved by comparing the load-bearing capacity of clad and unclad flawed plates and the results are presented and discussed below.

\section{RADIATION EFFECTS ON CLADDING}

\section{MATERIALS}

The specimens were taken from commercially produced stainless steel cladding overlaid on a pressure vessel steel plate. Three layers of cladding were applied to provide adequate thickness $(-20 \mathrm{~mm})$ to fabricate the test specimens. The three-wire series-arc procedure, developed by Combustion Engineering, Inc., Chattanooga, Tennessee, produced highly controlled weld chemistry, microstructure, and fracture properties in all three layers of the weld. Various combinations of types 308, 309, and 304 stainless steel wires were used in the three layers of cladding. The cladding was given a postweld heat treatment (PWHT) equivalent to $40 \mathrm{~h}$ at $621^{\circ} \mathrm{C}$. During cladding, the deltaferrite content was monitored with a Fischer Ferritescope. The ferrite numbers (which correspond roughly to-percentages of ferrite) varied from 7.5 to 10 throughout the three layers of the cladding. The photomicrograph of this cladding (Fig. 1) shows a distribution of delta-ferrite in an austenitic matrix quite typical of microstructures seen in good practice commercial weld overlay cladding in reactor pressure vessels.1-3 


\section{IRRADIATION HISTORY}

The specimens were irradiated in three capsules by Materials Engineering Associates in the core of the 2-MW pool reactor (UBR) at the Nuclear Science and Technology Facility in Buffalo, New York. Each of the first two capsules contained $20 \mathrm{CVN}$ and six miniature tensile (MT) specimens. The third capsule contained 240.5 TCS specimens, of which èight specimens were fabricated from the three-wire cladding, while the remaining specimens were from single-wire cladding. All capsules were instrumented with thermocouples and dosimeters and the specimens resided in a mixed helium and air environnent during the irradiation. Each capsule was rotated $180^{\circ}$ at least once during its irradiation exposure for side-to-side fluence balancing. Irradiation temperatures were maintained at $288 \pm 11^{\circ} \mathrm{C}$. The average fluences for the three capsules were $2.14 \pm 88,5.56 \pm 58$, and $2.36 \pm 68 \times 10^{29}$ neutrons $/ \mathrm{cm}^{2}$ (>1 MeV), respectively. These fluences are for a calculated spectrum based on $\mathrm{Fe}, \mathrm{Ni}$, and Co dosimetry wires.

\section{RESULTS AND DISCUSSION}

Effect of Irradiation on Tensile Propercies: The yield strength of three-wire stainless steel cladding increased due to radiation exposure. The effects were greater at room temperature and below (Fig. 2); e.g., at the fluence of $2 \times 10^{19}$ neutrons $/ \mathrm{cm}^{2}$ the yield strength increased by 9,20, and 288 at test temperatures of $288^{\circ} \mathrm{C}$, room temperature, and $-125^{\circ} \mathrm{C}$, respectively. At the higher fluence level of $5 \times 10^{19}$ neutrons $/ \mathrm{cm}^{2}$, the yield strength increased by 6,16 , and 348 at the test temperatures of $288^{\circ} \mathrm{C}$, room temperature, and $125^{\circ} \mathrm{C}$, respectively. Hence, it can be seen that most of the radiation damage occurred at the first fluence level; increasing the fluence by a factor of 2.5 did result in a relatively smaller radiation damage increase. The effects of irradiation on the ultimate strength and ductility were insignificant or very smal1 (Fig. 3).

Effect of Irradiation on Charpy Impact Properties: Irradiation of the three-wire stainless steel cladding specimens at $288^{\circ} \mathrm{C}$ to fluence levels of 2 and $5 \times 10^{19}$ neutrons $/ \mathrm{cm}^{2}(>1 \mathrm{MeV})$ resulted in decreases of the CVN uppershelf energy by 15 and 208 and increases of the $41-\mathrm{J}$ transition temperature by 13 and $28^{\circ} \mathrm{C}$, respectively (Fig. 4). Figure 4 shows that increasing irradiation from 2 to $5 \times 10^{19}$ neutrons $/ \mathrm{cm}^{2}$ further degraded the three-wire stainless steel cladding. Irradiation also degraded the CVN lateral expansion significantly (Fig. 5). The upper-shelf lateral expansion was reduced by 43 and 418 at the low and high fluences, respectively. Furthermore, the $0.38-\mathrm{mm}(0.015-$ in.) transition temperature shifts were 41 and $46^{\circ} \mathrm{C}$ for the low and high fluences, respectively. Table 1 also provides the curve fit results for the unirradiated and irradiated CVN test results. These results are in general agreement with those for the single-wire cladding produced with good welding practice. $1-3$

Effect of Irradiation on Ductile Fracture Toughness and Tearing Modulus: Results of the $0.51 \mathrm{CS}$ fracture toughness specimens fabricated from three-wire series-arc stainless steel cladding shows the following. Irradiation exposure to an average fluence of $2.41 \times 10^{19}$ neutrons $/ \mathrm{cm}^{2}$ ( $>1 \mathrm{MeV}$ ) resulted in a consistent decrease in the initiation ductile fracture toughness, $J_{I c}$, at test 
temperatures of $-75^{\circ} \mathrm{C}$, room temperature, $120^{\circ} \mathrm{C}$, and $288^{\circ} \mathrm{C}(\mathrm{Fig}$. 6). This is in agreement with the reduction in both the CVN upper-shelf energy and lateral expansion discussed above. However, the percent reduction in initiation toughness of the $0.5 T C S$ specimens is greater than that of the CVN impact energy but closer to that percent reduction of the CVN lateral expansion. Figure 6 also shows that the initiation toughness, JIc, of both unirradiated and irradiated specimens increased from high temperature to a peak at about ambient temperature and then decreased at low temperatures similar to the ductile behavior shown in Fig. 3. Radiation exposure at $288^{\circ} \mathrm{C}$ has also resulted in a consistent decrease in the tearing modulus at test temperatures from $-75^{\circ} \mathrm{C}$ to $288^{\circ} \mathrm{C}$. An example of the J-integral vs crack extension of two specimens tested at $120^{\circ} \mathrm{C}$ is shown in $\mathrm{Fig} .7$.

\section{CONCLUSIONS AND DESCRIPTION OF FUTURE WORK}

The effects of neutron irradiation on three-wire stainless steel weld cladding, prototypical of commercial light water reactor (LWR) materials, were evaluated at a wide range of test temperatures for conditions similar to those at the end of life of an LWR. The yield strength of this cladding increased with irradiation exposure; the increase rate was appreciably higher at low temperatures (room temperature and below). However, the effects of irradiation on the ultimate tensile strength and ductility (both uniform and total elongation) were insignificant.

All the unirradiated and irradiated three-wire cladding specimens exhibited ductile-to-brittle transition behavior similar to that seen earlier for the single-wire cladding. Again, this was also attributed to the dominance of failure of delta-ferrite at lower temperatures. The upper-shelf energy was reduced by 15 and 208, while the upper-shelf lateral expansion was reduced 43 and 418 , at 2.14 and $5.56 \times 10^{19}$ neutrons $/ \mathrm{cm}^{2}(>1 \mathrm{MeV})$, respectively. The $41-\mathrm{J}$ transition temperature shifts were 13 and $28^{\circ} \mathrm{C}$ for the low and high levels of fluence, respectively.

Irradiated $0.5 \mathrm{TCS}$ specimens tested from -75 to $288^{\circ} \mathrm{C}$ showed consistent decreases in both ductile initiation fracture toughness and tearing modulus in qualitative agreement with observed decreases in Charpy impact energy and lateral expansion.

It must be stressed that the results presented and discussed in this paper are only for a single case of a three-wire stainless steel cladding; hence, no conclusions can be drawn for different material chemistries and/or welding procedures.

Additional work in progress includes testing of precracked CVN and 12.5-mm compact specimens ( $0.5 \mathrm{TCS}$ ) from the single-wire cladding. Furthermore, stainless steel cladding from the decommissioned West German Boiling Water Reactor at Gundremmingen will be examined using subsize specimen techniques to compare to our test reactor data. The subsize specimens will be machined from the recently acquired four trepans cut from the decommissioned reactor.

\section{DISCLAIMER}




\section{CLAD PLATE EXPERIMENTS}

A small crack near the inner surface of clad nuclear $R^{p V s}$ is an important consideration in the safety assessment of the structural integrity of the vessel. The behavior of such flaws is relevant to the PTS scenario and to the plant life extension issue. There are considerable experimental results which have shown that, in the absence of cladding, a small surface flaw in an embrittled material subjected to severe thermal shock will become a long flaw. One example from Ref. 5 is shown in Fig. 8, which shows the extensive propagation and bifurcation on the surface of the TSE-7 cylinder originatirg from a $19-\mathrm{mm}$ semicircular surface flaw. Other examples are given in Ref. 6 .

There is a dearth of information on the behavior of small flaws in the presence of cladding, and questions remain about the role a tough surface cladding will play in preventing the propagation of small flaws along the surface. A clad plate research program was conducted as part of Oak Ridge National Laboratory's HSST program in order to investigate the behavior of small flaws in the presence of cladding. The objectives of this research were achieved by comparing the load-bearing capacicy of clad and unclad flawed plates.

\section{EXPERIMIENT DESCRIPTION AND RESULTS}

A special plate specimen made of a typical RPV steel conforming to ASTM Specification for Pressure Vessel Plates, Alloy Steels, Quenched and Tempered, Manganese-Molybdenum and Manganese-Molybdenum-Nickel (A 533) Grade B has been developed to investigate the effects of cladding on the behavior of flaws (Fig. 9). It was commercially clad using the three-wire series-arc technique and stainless steel types 308,309 , and 312 weld wires. The three-wire seriesarc technique was used in some of the older vessels.

CVN impact tests were performed on the cladding, heat-affected zone (HAZ), and base metal with specimens oriented in a direction corresponding to the flaw propagating along the surface of the clad-plate specimens (Fig. 10). Results of CVN impact testing on specimens oriented in a direction corresponding to the electron beam-induced flaw propagating in the thickness orientation were similar. ${ }^{7}$ The CVN test results show that the cladding has a substantially lower ductile-to-brittle transition temperature than base metal as measured by the Charpy impact energy. The Charpy transition of the HAZ is also noticeably lower than that of the base metal. This is principally the result of the special heat treatment given to the base metal to raise its transition temperature. Details of the plate fabrication and heat treatment can be found in Ref. 7. Tests to determine nil-ductility temperature (NDT) using specimen P-3 according to the ASTM Test for Conducting Drop-Weight Test to Determine NDT of Ferritic Steels (E 208) were also performed and resulted in an NDT of $36^{\circ} \mathrm{C}$ for the base metal.

An electron beam weld is introduced into the base metal to provide a crack initiation site. The initially unflawed plate is loaded in four-point bending to approximate the stresses due to PTS. To initiate a sharp flaw, the plates were hydrogen charged while the load was maintained constant. The 
specific purpose of this test was to determine the arrest capacity of clad plates with various amounts of stored energy.

The pop-in, arrest loads, and corresponding crack lengths for the four plates tested at room temperature are shown schematically in Fig. 11 . It may be noted that, as the potential energy stored in the plate increased, the length of the arrested flaw also increașed as shown schematically by the shaded flaw shape in Fig. 11. Photographs of actual fracture surfaces of the plates are shown in Figs. $1 \ddot{i}$ and 13 . From these photographs it may be noted that in almost all cases a surface layer composed of HAZ and cladding arrested the flaw and prevented its propagation along the surface, causing it to tunnel below the surface.

\section{DISCUSSION}

The tough surface layer of cladding and HAZ seemed to have contributed significantly to the load-bearing capacity of the plates by arresting flaws at loads and temperatures that have ruptured unclad plates, as seen by comparing the results of the tests on clad plates CP-15, CP-17, CP-19, and unclad plate CP-21. In fact, the clad plate CP-19 arrested a flaw subjected to a driving force (as measured by the initial load) almost 508 higher than that which broke an unclad plate. Moreover, the residual load-bearing capacity of plates (even with fairly large flaws) as measured by the arrest loads was generally greater than required to break the unclad plate (Fig. 11).

The HAZ played a prominent role in enhancing the load-carrying capacity of the clad plates. As measured by the CVN impact energy, the HAZ is the toughest of the three metallurgical zones of the clad plate specimens at $25^{\circ} \mathrm{C}$, while the cladding is toughest at $-25^{\circ} \mathrm{C}$. It is not clear at this time whether cladding alone, without benefit of the tough strong HAZ which played a pronounced role in arresting propagating flaws, would have also elevated the load-bearing capacity beyond that of the unclad plate. In the case of radiation-embrittled RVPs, the HAZ will most likely undergo toughness degradation similar to that of the base metal, and therefore may not play such a prominent role in arresting propagating flaws.

\section{ACKNOWLEDGMENTS}

The authors gratefully acknowledge the personnel of Materials Engineering Associates, particularly J. R. Hawthorne, for capsule fabrication and Irradiation. We acknowledge T. N. Jones, R. L. Swain, and E. T. Manneschmidt for their experimental assistance; and P. H. Wilson, V. M. Wright, and D. J. Walmsley for editing and preparing the manuscript. We also acknowledge the support of our technical monitor, Michael Mayfield, the Materials Engineering Branch Chief, Chuck Serpan, Jr., and the U.S. Nuclear Regulatory Commission. 


\section{REFERENCES}

1. W. R. Corwin et al., "Fracture Properties of a Neutron-Irradiated Stainless Steel Submerged Arc Weld Cladding Overlay," pp. 26-47 in NUREG/CP0058 , Vol. 4, Proceedings of the Twelfth Water Reactor Safety Research Information Meeting, Gaithersburg. Maryland, October 22-26, 1984.

2. W. R. Corwin et al., "Charpy Toughness and Tensile Properties of a Neutron-Irradiated Stainless Steel Submerged-Arc Weld Cladding Overlay," pp. 951-71 in Effects of Radiation on Materials: Twelfth International Symposium, ASTM STP 870, F. A. Garner and J. S. Perrin, eds., American Society for Testing and Materials, Philadelphia, 1985.

3. W. R. Corwin et al., "Fracture Behavior of a Neutron-Irradiated Stainless Steel Submerged Arc Weld Cladding Overlay," Nucl. Eng. Des. 89, 199221 (1985).

4. F. M. Haggag et al., "Effects of Irradiation on Strength and Toughness of Commercial LWR Vessel Cladding", Pp. 177-193 in NUREG/CP-0091, Vol. 2, RF, R5, Proceedings of the Fifteenth Water Reactor Safety Information Heeting, Gaithersburg, Maryland, October 26-29, 1987.

5. R. D. Cheverton et al., Pressure Vessel Fracture Studies Pertaining to the PWR Thermal-Shock Issue: Experiment TSE-7, NUREG/CR-4304 (ORNL-6177), Oak Ridge National Laboratory, 1985.

6. S. K. Iskander, "A Method of LEFM Analysis of RFV During SBLOCA," Int. J. Pressure Vessels Piping 25, 279-298 (1986).

7. S. K. Iskander et al., "Effect of Stainless steel Weld Overlay Cladding on the Structural Integrity of Flawed Steel Plates in Bending Series $2^{n}$ (to be published). 
Table 1. Charpy impact test results for stainless steel three-wire series-arc cladding

\begin{tabular}{|c|c|c|c|c|c|c|}
\hline \multirow{3}{*}{ Orientation ${ }^{a}$} & \multirow{3}{*}{$\begin{array}{c}\text { Neutron } \\
\text { fluence, } \\
\text { neutrons } / \mathrm{cm}^{2} \\
(>1 \mathrm{MeV})\end{array}$} & \multirow[t]{3}{*}{$*$} & \multirow{2}{*}{\multicolumn{2}{|c|}{$\begin{array}{l}\text { Transition } \\
\text { temperature } \\
\text { criterion } \\
\left({ }^{\circ} \mathrm{C}\right)\end{array}$}} & \multicolumn{2}{|c|}{$\begin{array}{c}\text { Energy } \\
(\mathrm{J})\end{array}$} \\
\hline & & & & & \multirow{2}{*}{$\begin{array}{l}\text { Upper } \\
\text { shelf }\end{array}$} & \multirow{2}{*}{$\begin{array}{l}\text { Lower } \\
\text { shelf }\end{array}$} \\
\hline & & & $41 \mathrm{~J}$ & $68 \mathrm{~J}$ & & \\
\hline LS & 0 & & -41 & 6 & 82 & 13 \\
\hline LS & $2 \times 10^{19}$ & & -28 & 56 & 70 & 9 \\
\hline LS & $5 \times 10^{19}$ & & -13 & -- & 68 & 12 \\
\hline LT & 0 & & -28 & 11 & 88 & 14 \\
\hline $\mathrm{TL}$ & 0 & & -40 & 4 & 86 & 16 \\
\hline TS & 0 & & -55 & 7 & 83 & 12 \\
\hline
\end{tabular}

$a_{W i t h}$ respect to the base metal where $L$ is the rolling as well as the welding direction. 


\section{List of Figures}

Fig. 1. Microstructure of three-wire stainless steel cladding weld overlay is typical of reactor pressure vessel cladding with delta-ferrite in austenitic matrix, good quality comnercial cladding.

Fig. 2. Effect of neutron irradiation at $288^{\circ} \mathrm{C}$ on the yield strength of three-wire stainless steel cladding (yield strength vs test temperature).

Fig. 3. Effect of irradiation on the ultimate strength and elongation of three-wire stainless steel cladding: (a) ultimate strength vs temperature;

(b) total elongation vs temperature.

Fig. 4. Effect of irradiation on the Charpy impact energy of three-wire stainless steel cladding.

Fig. 5. Effect of irradiation on the Charpy V-notch lateral expansion of three-wire stainless steel cladding.

Fig. 6. Effect of irradiation on the ductile initiation fracture toughness of three-wire stainless steel cladding.

Fig. 7. Effect of irradiation on the tearing modulus of three-wire stainless steel cladding.

Fig. 8. Developed view of inner surface of the TSE-7 cylinder in which the 19-mm-radius semicircular flaw propagated on the surface to become a long flaw during the test (Cheverton et al., 1985).

Fig. 9. Clad plate specimen.

Fig. 10. Charpy impact energy of base metal, heat-affected zone, and cladding used in the clad plates. Specimen orientation corresponds to electron beam-induced flaw propagating along the surface.

Fig. 11. Pop-in, arrest loads, and corresponding crack lengths for the four plates tested at room temperature.

Fig. 12. Fracture surfaces of clad-plate CP-17.

Fig. 13. Fracture surfaces of clad-plate CP-19. 


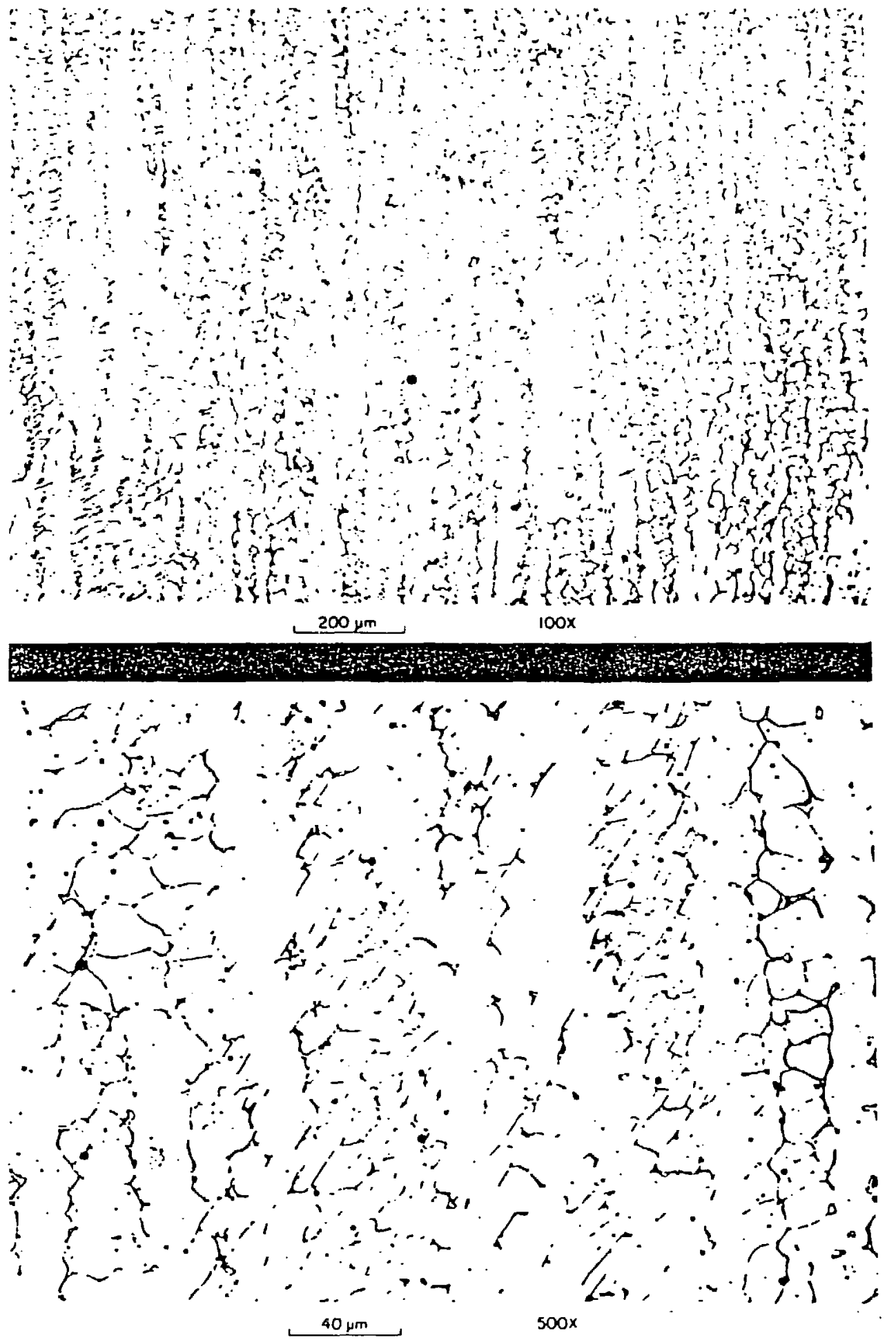

Fig. 1. Microstructure of three-wire stalniess sceel cladding weld overlay is typical of reactor pressure vessel cladding with delca. ferrice in austenitic matrix, good qualicy commercial cladding. 


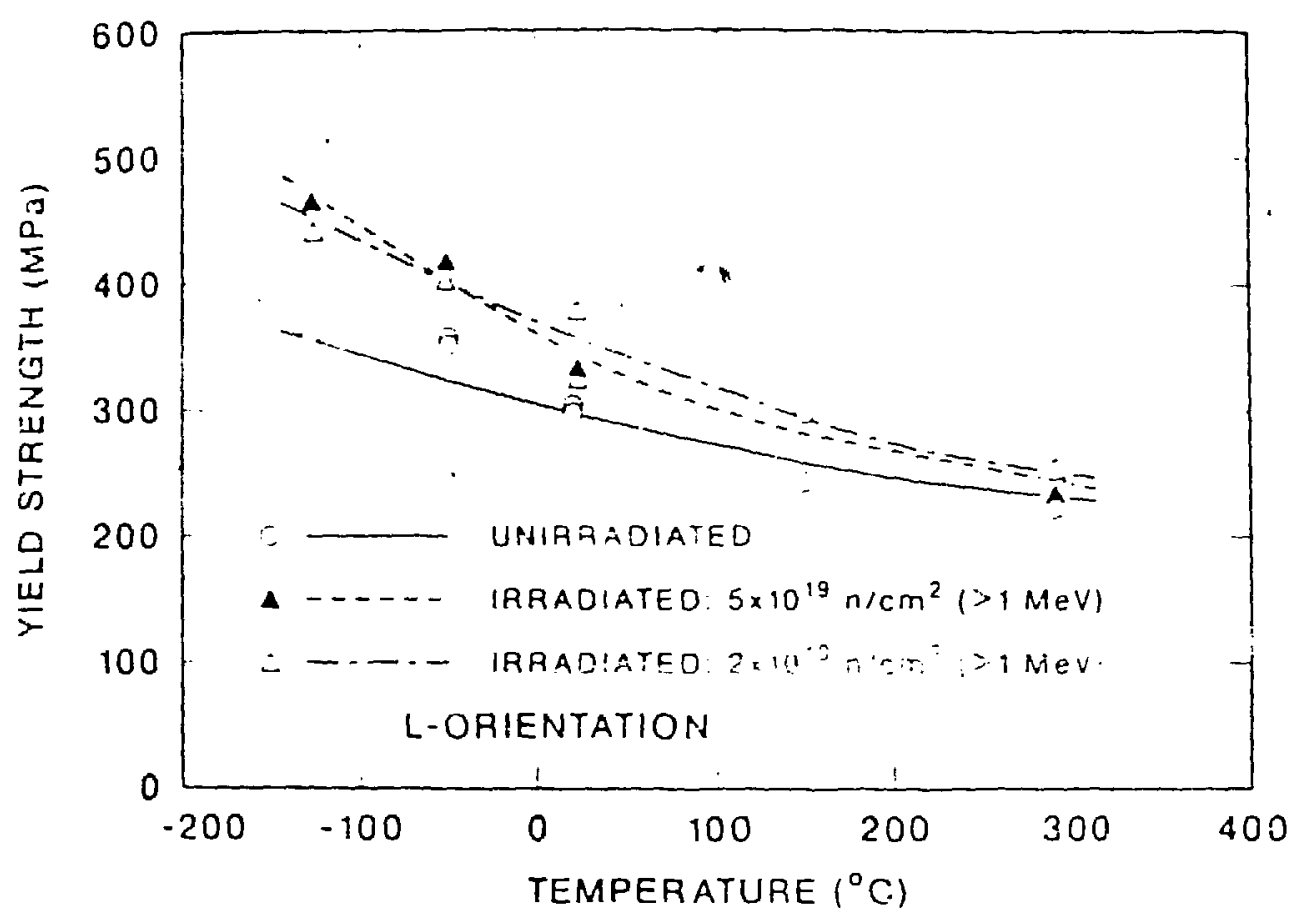

Fig. Effect of neutron irradiation at $288^{\circ} \mathrm{C}$ on the yield strength of three-wire stainless steel cladding (yield sirength vs test temperature). 


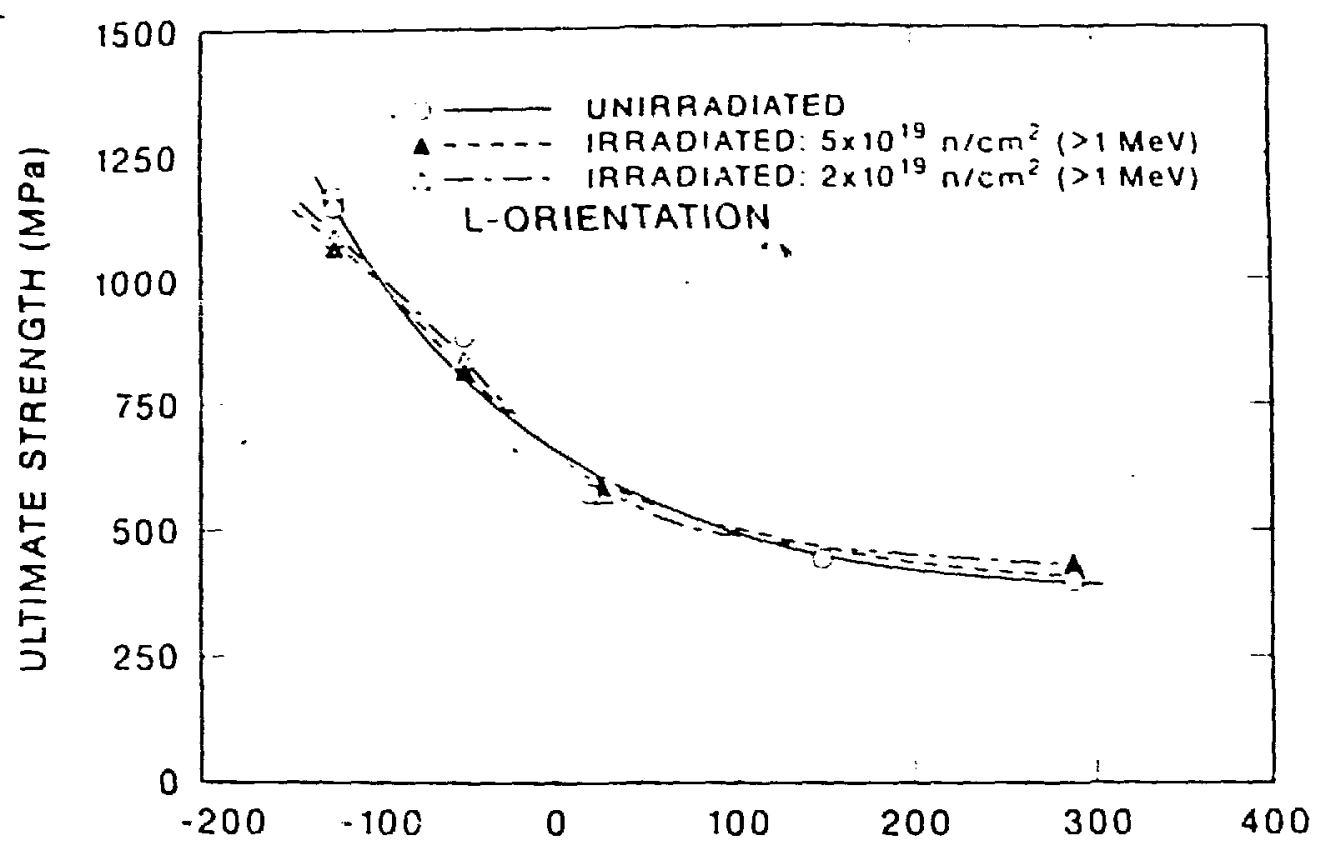

(a)

TEMPERATURE $\left({ }^{\circ} \mathrm{C}\right)$

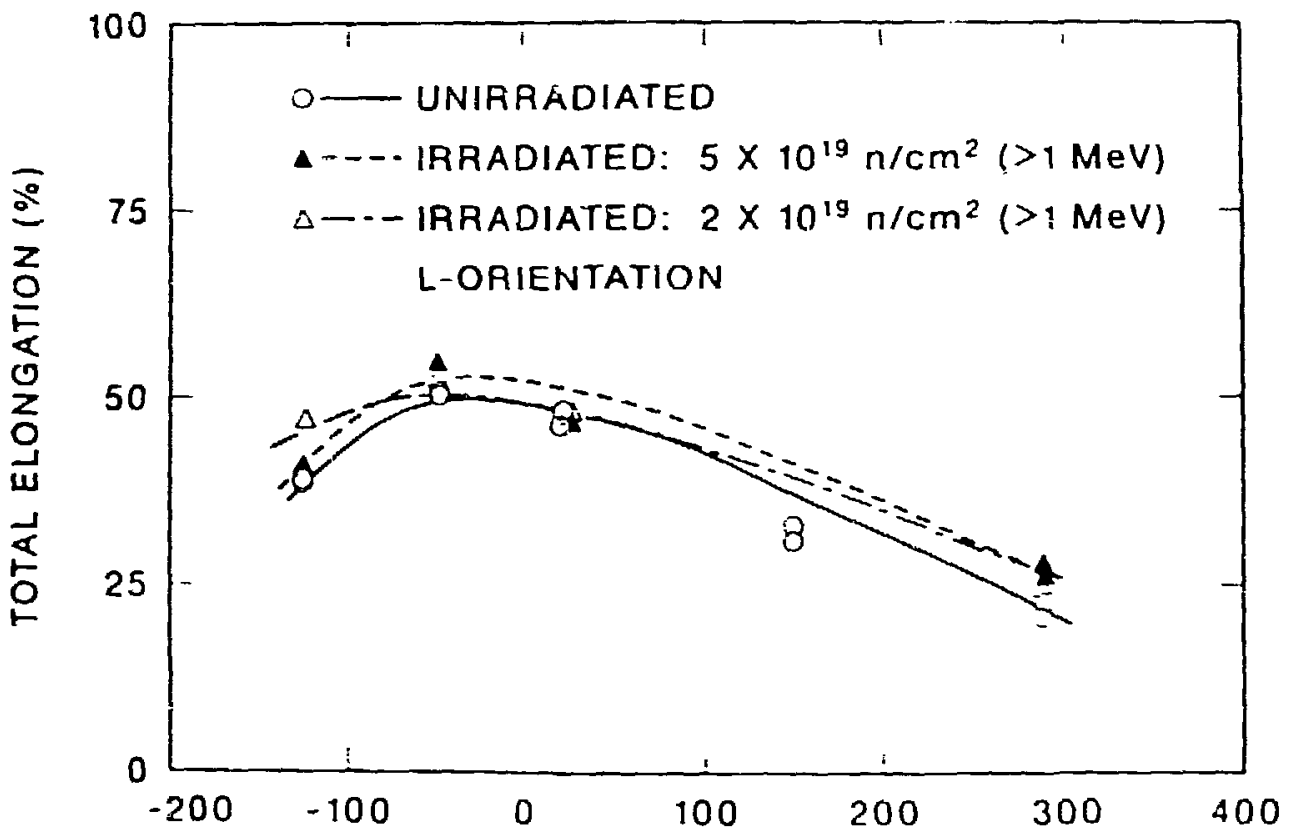

(b)

TEMPERATURE $\left({ }^{\circ} \mathrm{C}\right)$

Fig. 3. Effect of irradiation on the ultimate sizength and elongation of three-bire stainless stecl cladding: (a) vititnate strength us temperature; (b) total elongation vs cetrpezature. 


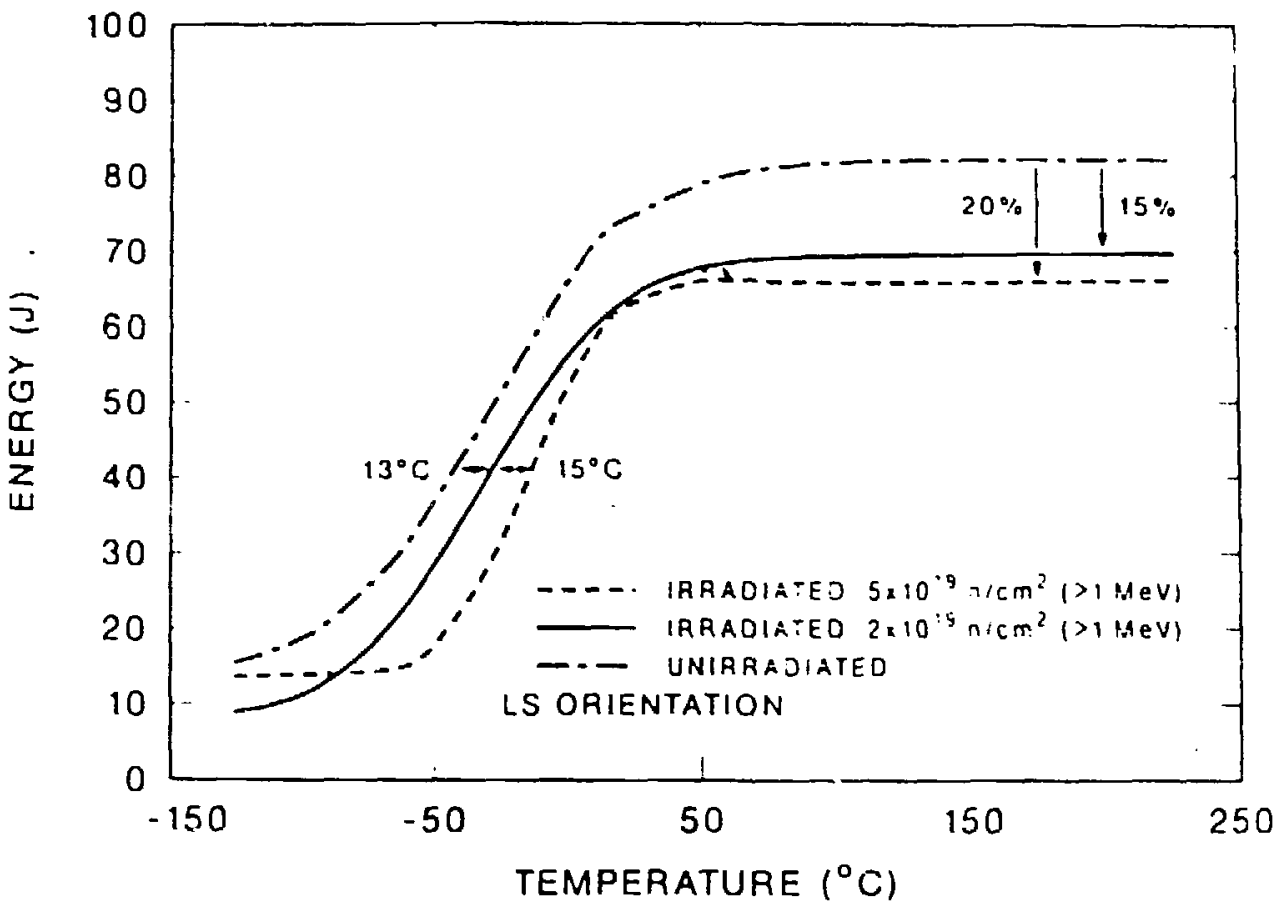

Fig. Af . Effect of irradiation on the Chappy impact toughness of three-wire, stainless steel cladding. 


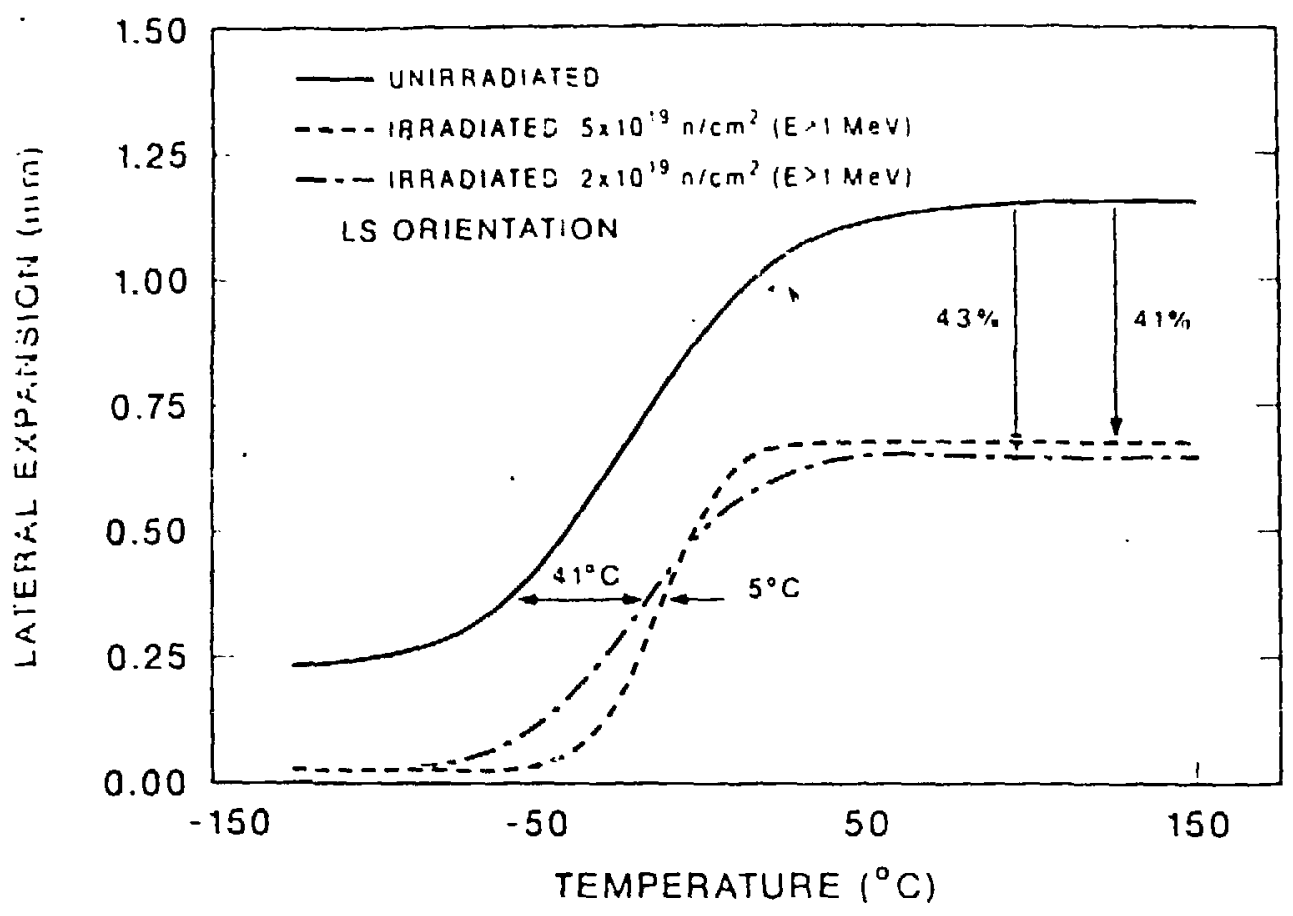

Fig. Effect of irradiation on the CVN lateral expansion of three-wire stainless steel cladding. 


\section{RADIATION EXPOSURE REDUCED THE JIC TOUGHNESS}

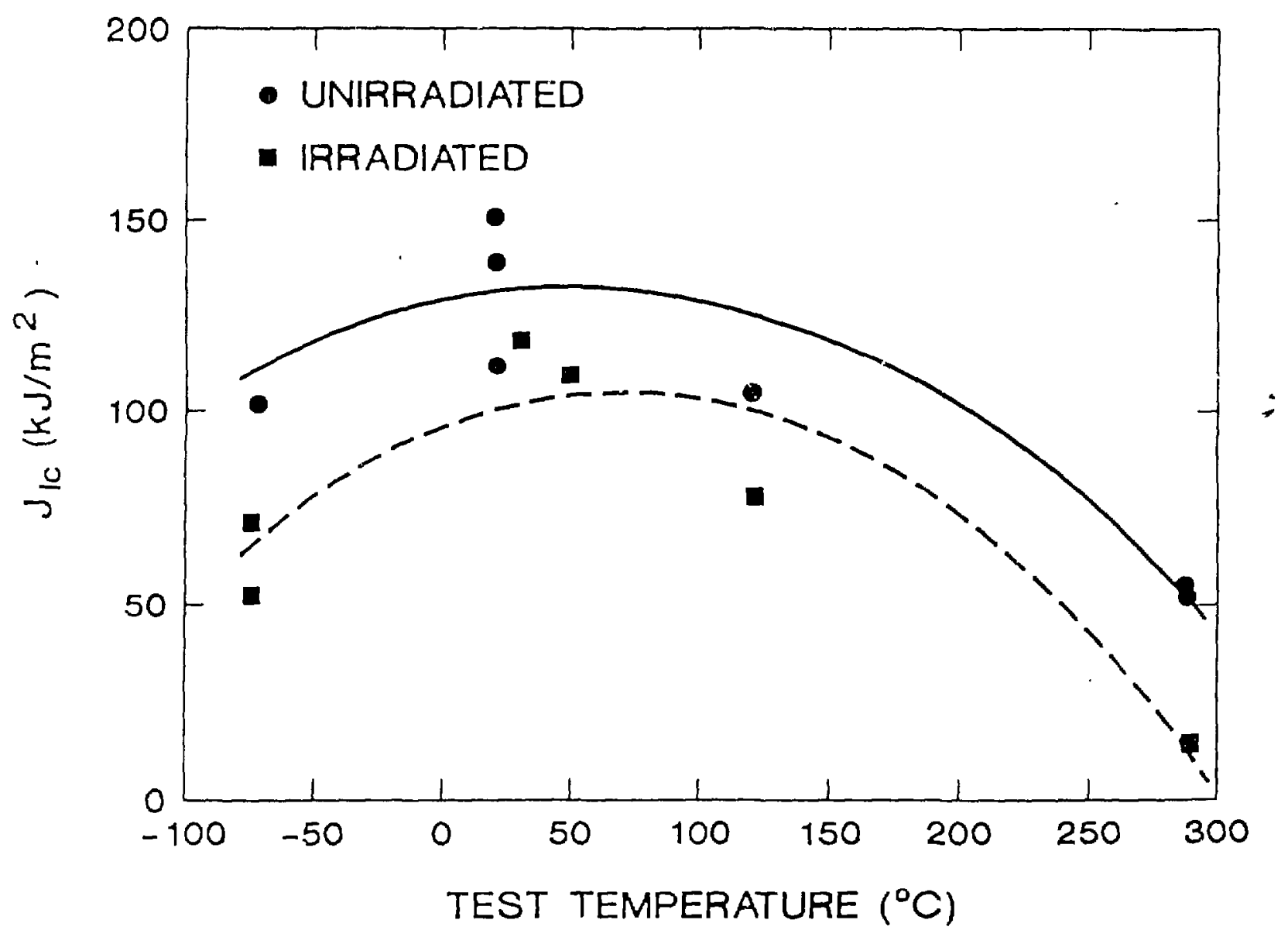




\section{RADIATION EXPOSURE REDUCED THE}

DOCTILE TEARING RESISTANCE

CRACK EXTENSION (in)

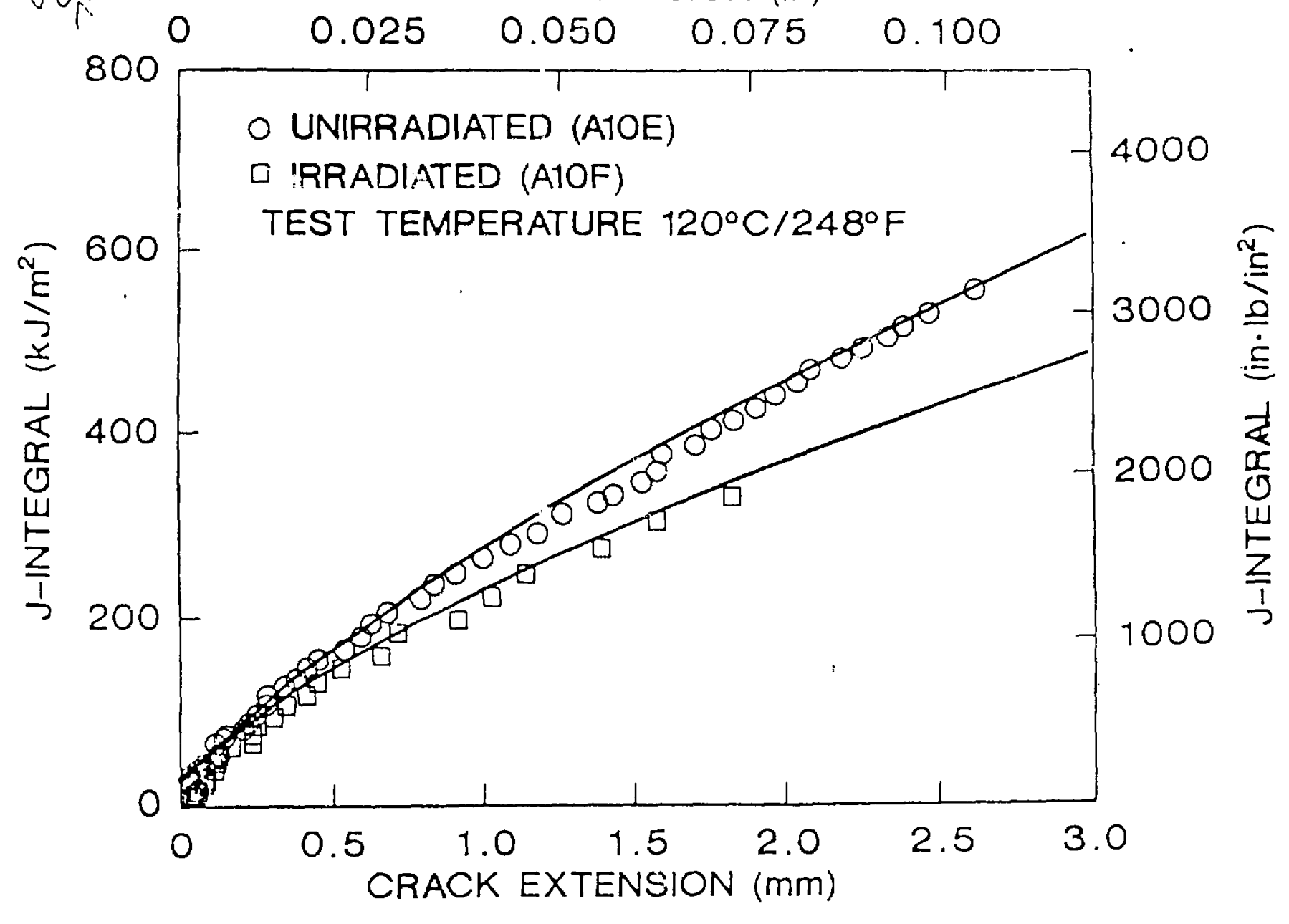


IN THE ABSENCE OF CLADDING SMALL

FLAWS HAVE POTENTIAL TO BECOME LONG FLAWS EXPERIMENTAL EVIDENCE FROM A TEST. ON AN INTERMEDIATE SIZED VESSEL

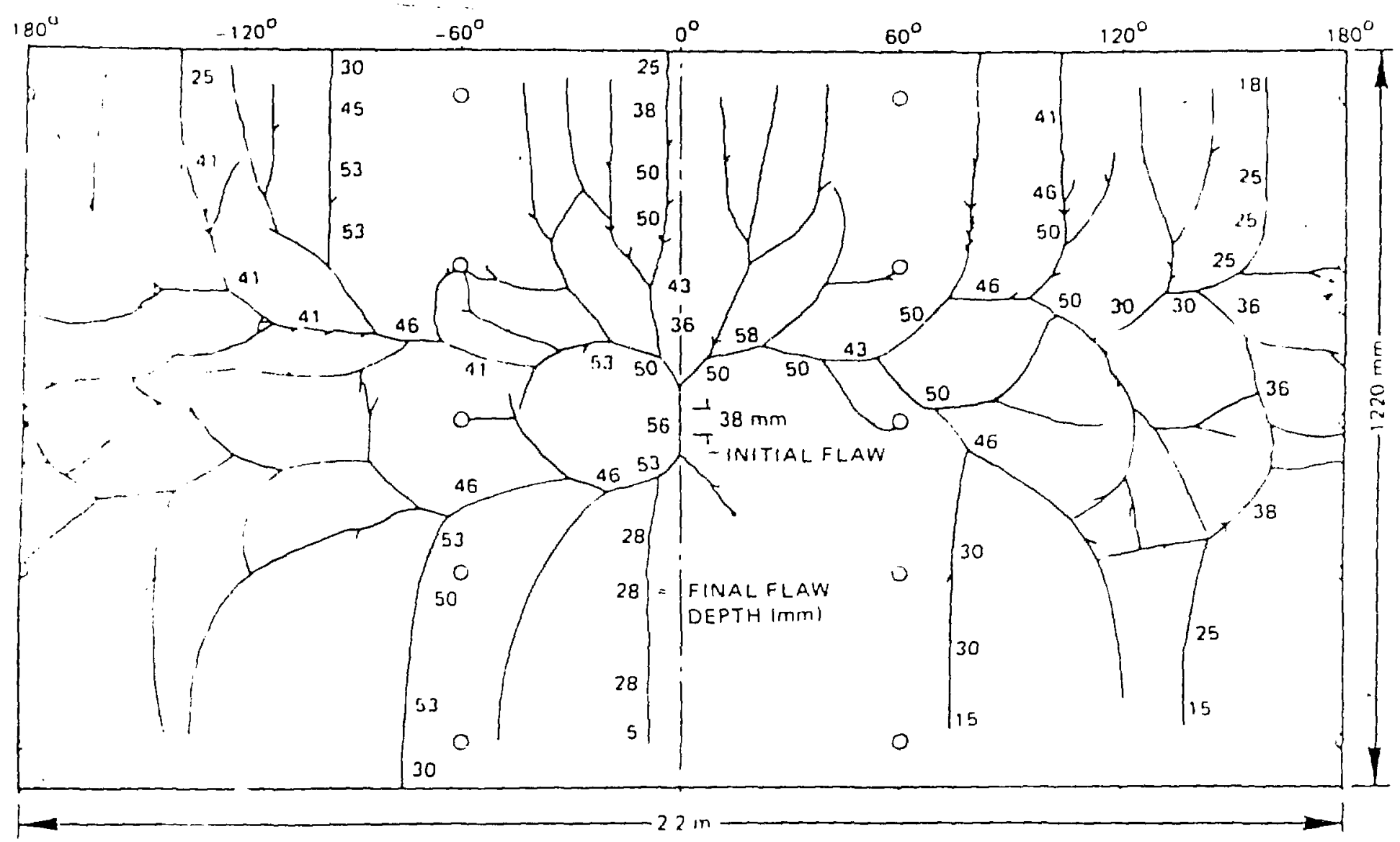




\section{CLAD PLATE PROGRAM'DESIGNED TO INVESTIGATE BEHAVIOR OF SMALL SURFACE FLAWS IN PRESENCE OF STAINLESS STEEL CLADDING}

- Does cladding have the potential of stopping small surface flaws from becoming long surface flaws?

- If small flaws are prevented from becoming long, the structural resistance is enhanced.

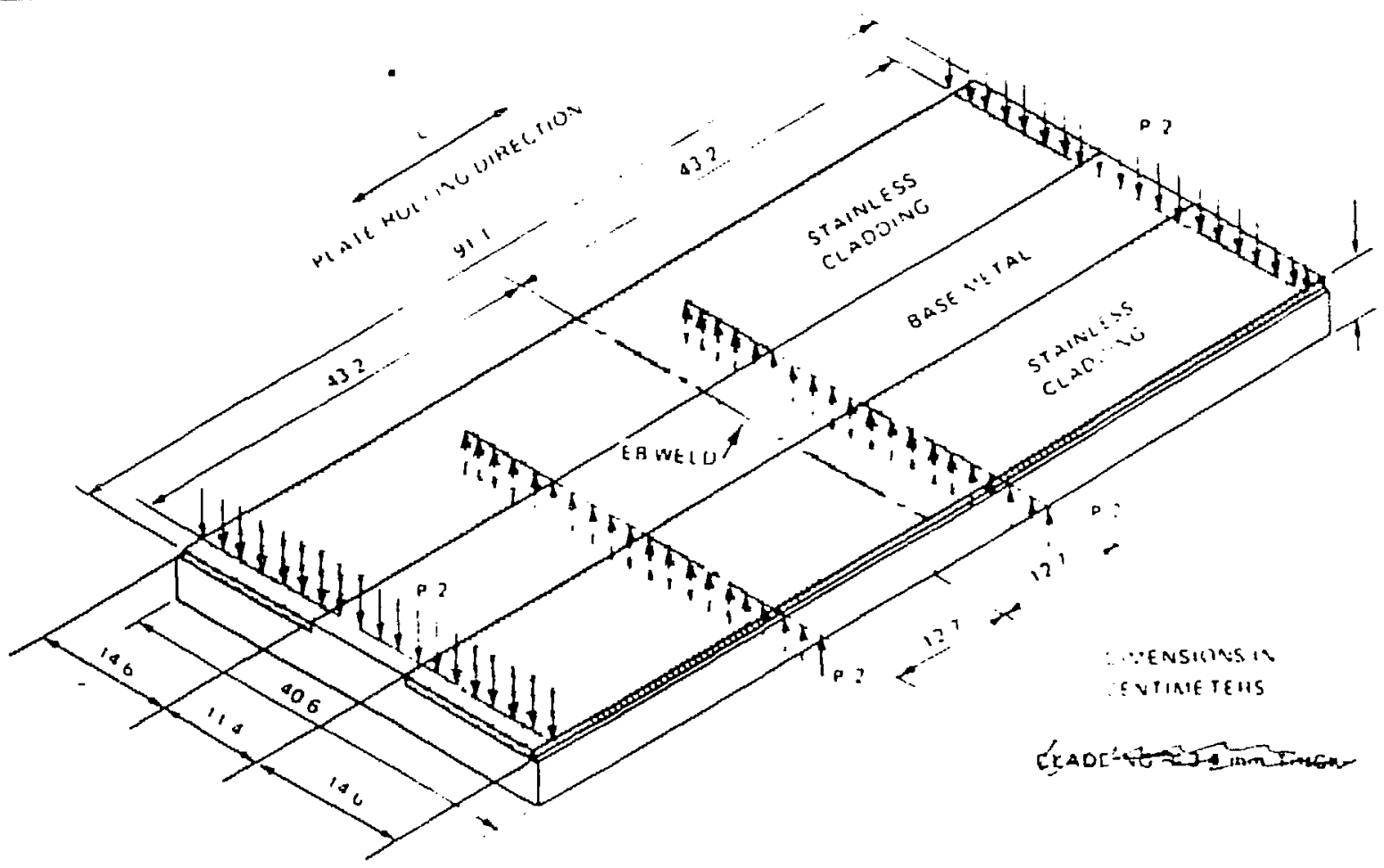


BASE METAL HAS BEEN HEAT-TREATED TO RAISE TRANSITION TEMPERATURE SO IT IS BRITTLE AT TEMPERATURES IN WHICH CLADDING IS TOUGH
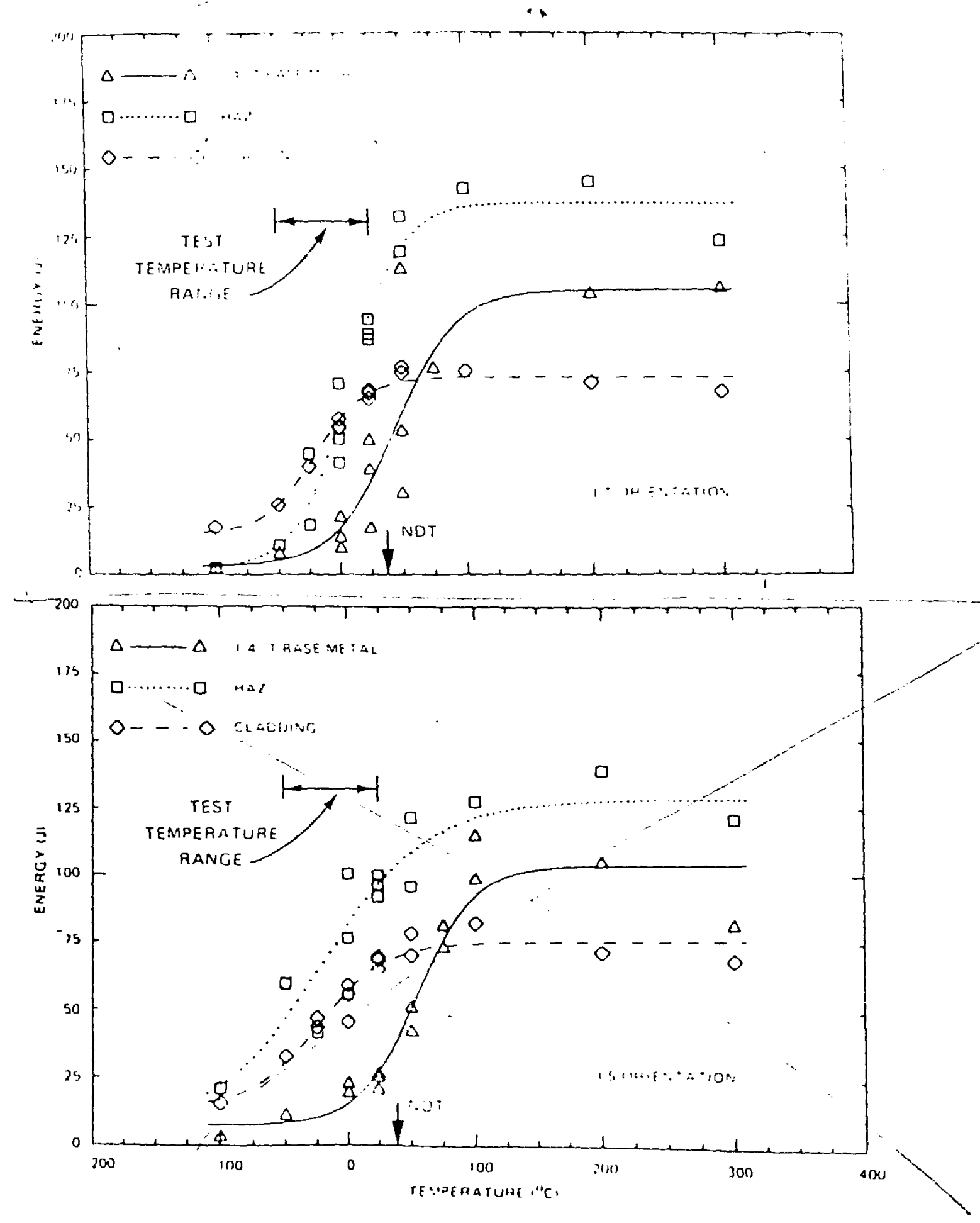
CLAD PLATES HAVE MAINTAINED STRUCTURAL INTEGRITY AT LOADS THAT HAVE RUPTURED AN UNCLAD PLATE TEST TEMPERATURE: (NDT-10) ${ }^{\circ} \mathrm{C}$

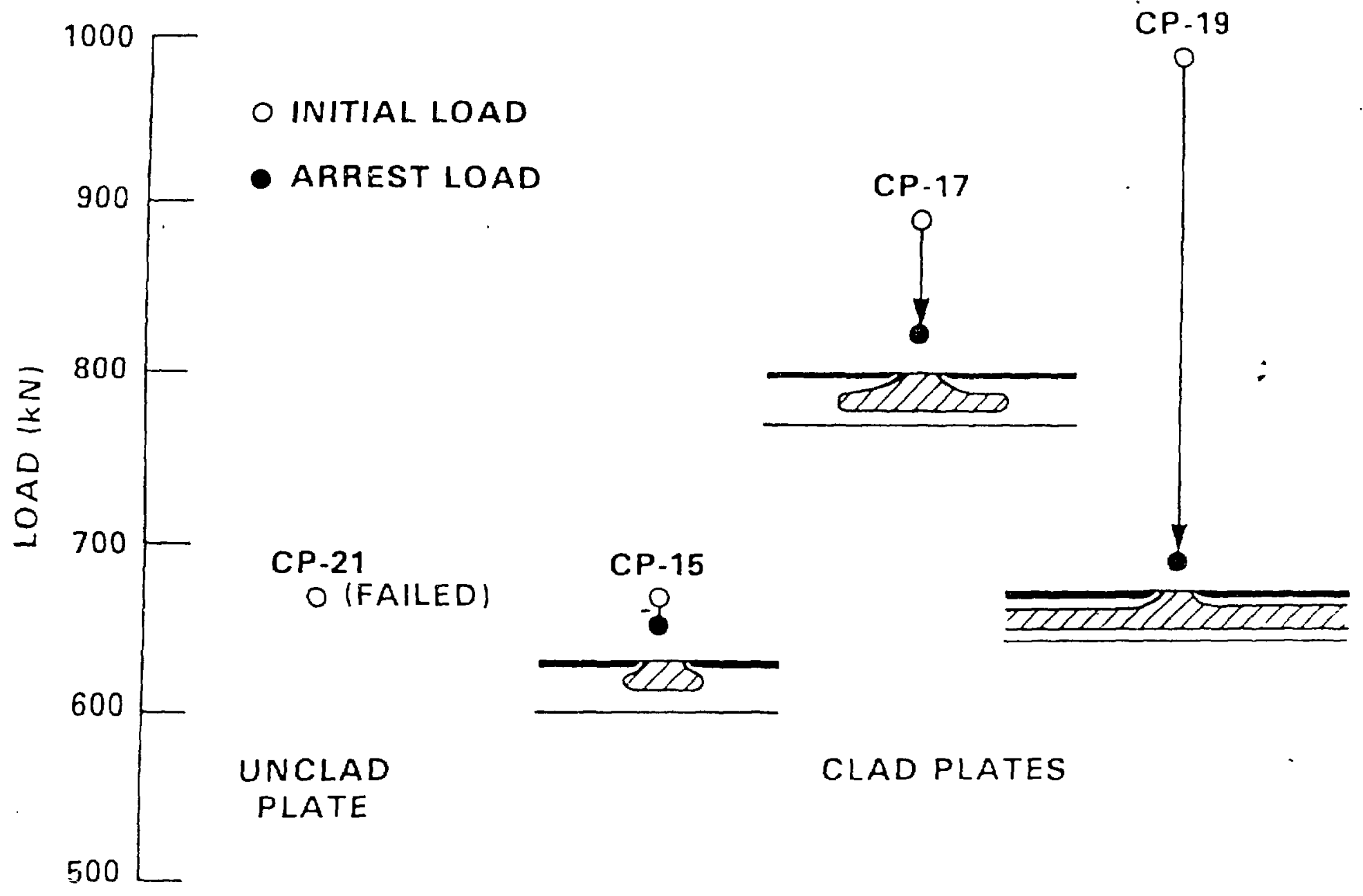




\section{RESIDUAL LOAD BEARING CAPACITY OF GTAINLESS-STEEL CLAD PLATES WITH LARGE BURIED FLAWS EXCEEDS THAT OF UNCLAD PLATES BY MORE THAN 20\% AT TEMPERATURES OF (NDT-10) ${ }^{\circ} \mathrm{C}$}

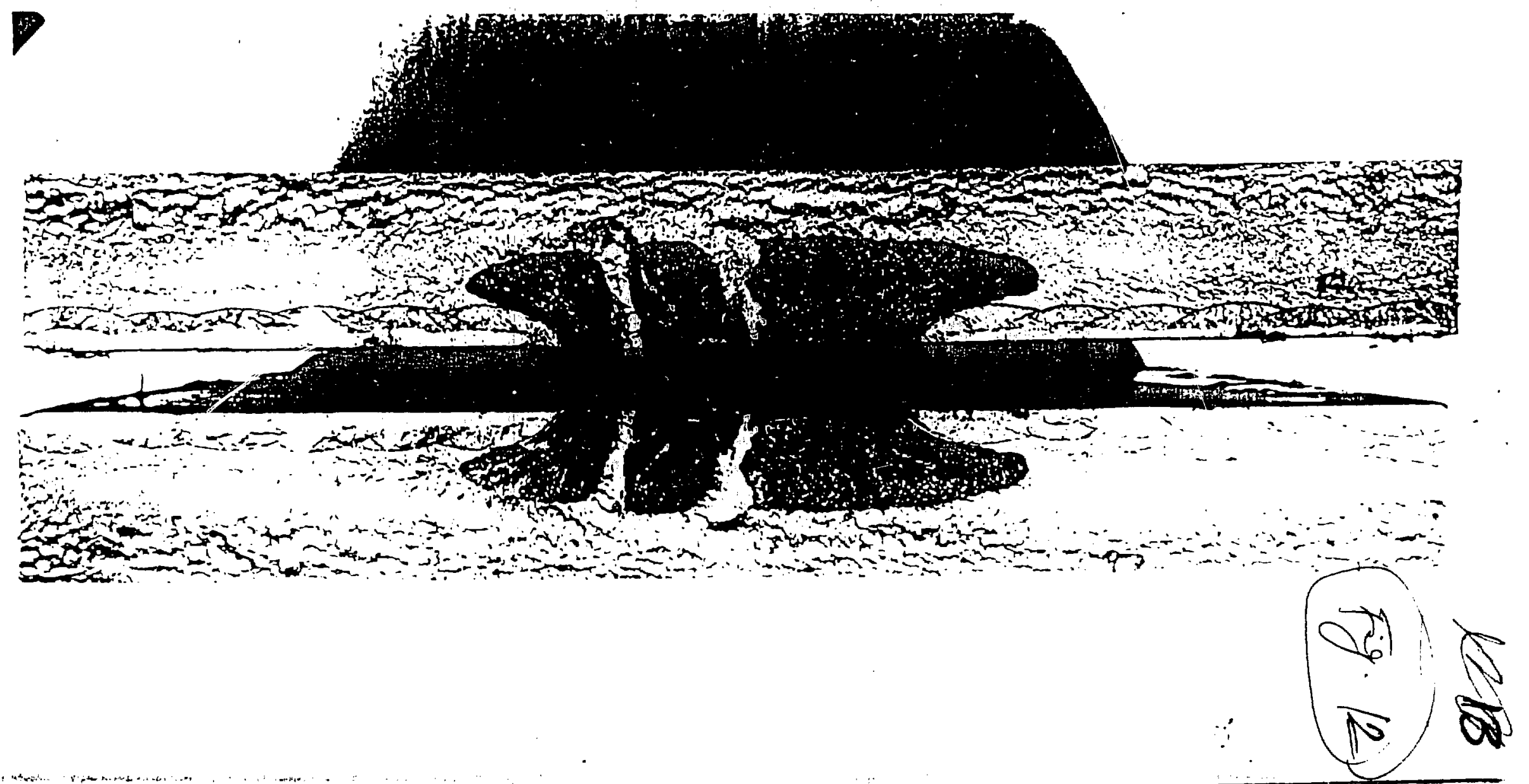




\section{TOUGH SURFACE LAYER MAINTAINS STRUCTURAL INTEGRITY AFTER TUNNELING BY PREVENTING FLAW FROM EXTENDING TO THE SURFACE}
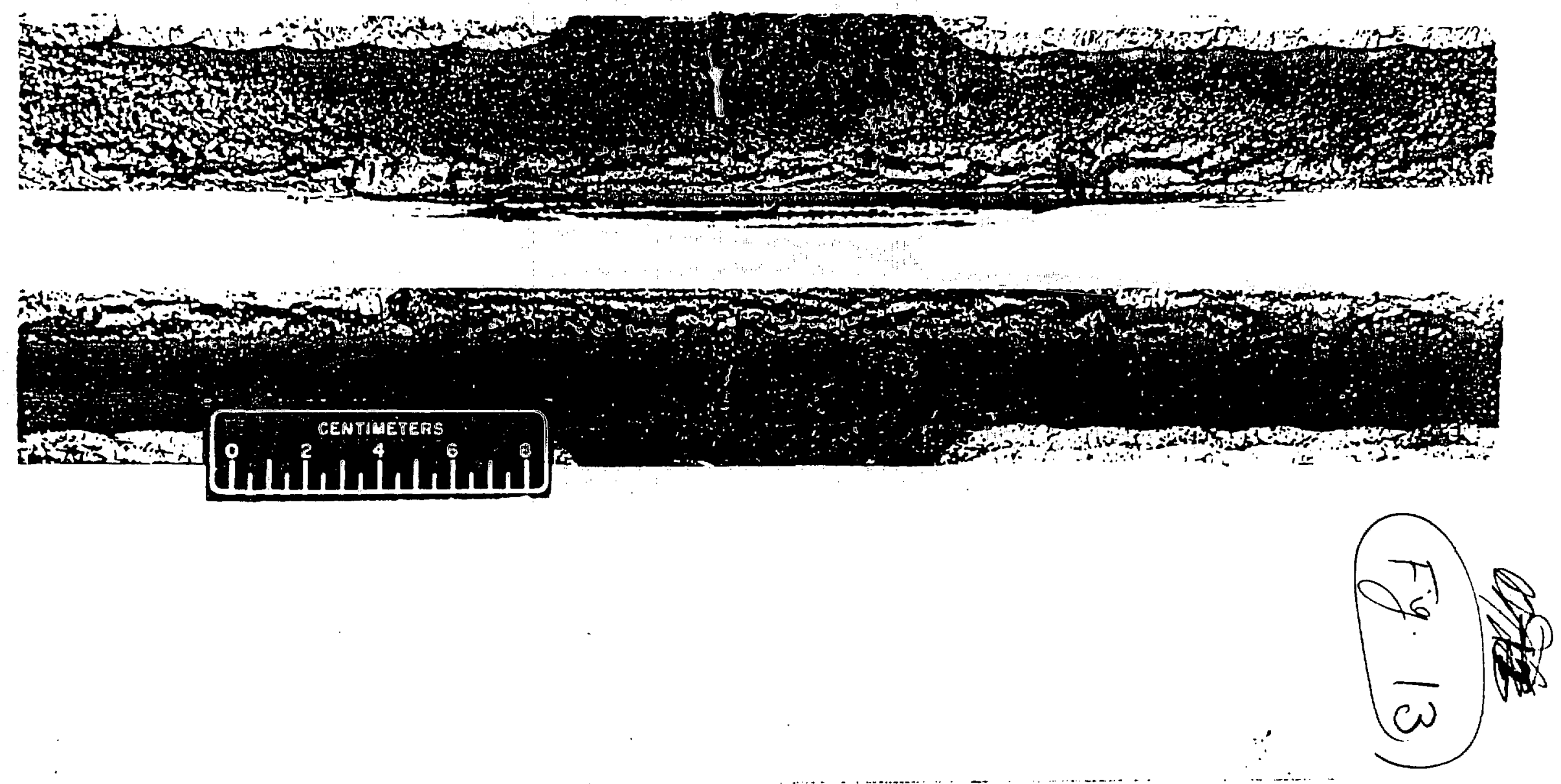